\title{
ECONOMETRIC MODELS AND THEIR ABILITY TO PREDICT GDP GROWTH OF THE CZECH REPUBLIC
}

\author{
[Ekonometrické modely a jejich schopnost předvídat růst HDP České republiky]
}

\author{
Milan Bouda ${ }^{1}$ \\ ${ }^{1}$ University of Economics in Prague, Faculty of Informatics and Statistics, W. Churchill Sq. 4, 13067 Prague, \\ Czech Republic. \\ Email:bouda.mil@seznam.cz
}

\begin{abstract}
The paper deals with forecasting the ability of the most common macroeconomic methods. The main goal is to predict the percentage GDP growth while using many methods and at the end assess the performance of these methods. The performance is measured by the Root Mean Square Error statistics. Methods used in this paper are: naive Auto Regression with one lag, Vector Auto Regression with two lags, Bayesian Vector Auto Regression with two lags, Dynamic Stochastic General Equilibrium (DSGE) and a DSGE- VAR model which obtains priors from a DSGE model and then estimates it like Vector Auto Regression. The next contribution of this paper is specification of a New Keynesian DSGE model and coding it in Matlab. Final results summarize the performance of each method. On the other hand, structural models as DSGE and DSGE-VAR perform better than a benchmark. In case of a DSGE model it is mainly caused by its structural nature. This model also contains forward looking variables which take into account the behavior of households and firms which are basic cornerstones of a NK DSGE model. The DSGE-VAR model performs better than a benchmark due to fact that priors are taken from the DSGE model. It means that structural information can be transferred using these priors. Nevertheless, according to the RMSE statistics the best performing method is the DSGE model.
\end{abstract}

Keywords: AR, VAR, BVAR, DSGE, DSGE-VAR.

JEL classification: E12, E17

Doručeno redakci: 29.8.2013; Recenzováno: 2.6.2014; 19.6.2014; Schváleno k publikování: 23.9.2014

\section{Introduction}

One of the biggest problems of currently used macroeconomic models is the ability to predict structural changes in the economy. This issue is a very hot topic in the academic sphere as well as in the national banks. Currently, the econometrics allows a specification of various kinds of models which can be used for forecasting and there is no general agreement which method is the best one. The motivation of this paper is to discuss all relevant methods and assess their prediction power. The main goal of this paper is to predict the GDP growth of the Czech Republic while using the following methods: naive Auto Regression with one lag (AR(1)) which is used as a benchmark, Vector Auto Regression (VAR), Bayesian Vector Auto Regression (BVAR), Dynamic Stochastic General Equilibrium (DSGE) and Dynamic Stochastic General Equilibrium - Vector Auto Regression (DSGE-VAR). The first mentioned naive $\mathrm{AR}(1)$ is a benchmark which is a challenge to overcome whilst using the other methods. The performance of these estimation methods is measured by the Root Mean Square Error (RMSE). A model with a lower RMSE is generally considered as a better. The main goal of the paper is to examine whether the basic versions of current econometric tools are able to predict structural changes in the economy. Finally, the prediction ability of all methods is assessed by the RMSE. Equally valuable is the specification and coding of the New Keynesian DSGE model of the Czech Republic which is taken from Galí (2008). 


\section{Root Mean Square Error (RMSE)}

This paper presents predictions of GDP using the advanced econometric methods. First, it is necessary to define the measure which is used as an assessment of accuracy. For this purpose the Root Mean Square Error (RMSE) is taken from Hušek (2007). RMSE is a frequently used measure of the differences between values predicted by a model or an estimator and the values actually observed. The RMSE measure quantifies the effectiveness of each econometric method and it allows comparison of these econometric methods. RMSE is defined as follows

$$
R M S E=\sqrt{\frac{\sum_{t=1}^{n}\left(y_{t}-\hat{y}_{t}\right)^{2}}{n}},
$$

where $t$ is the number of observation, $n$ is the total number of observations, $y_{t}$ is the actual value and $\hat{y}$ is the fitted value.

\section{Data}

The methods use the various variables. The first observed variable is Gross Domestic Product (GDP) and this variable is used in all models. The second observed variable is inflation. Time series are taken from the databases of the Czech National Bank called ARAD and the Czech Statistical Office. First, one has to transform variables into the appropriate form. The GDP is seasonally adjusted and in constant prices of year 2005. Next, the GDP is transformed into the year over year (YoY) percentage changes. Both variables are in quarterly frequencies and according to the KPSS test stationary. Figure 1 below shows the transformed GDP and inflation. The end of the time series is highlighted because this end will be estimated by different methods and these values will be used as a benchmark.

Figure 1: Both observed variables
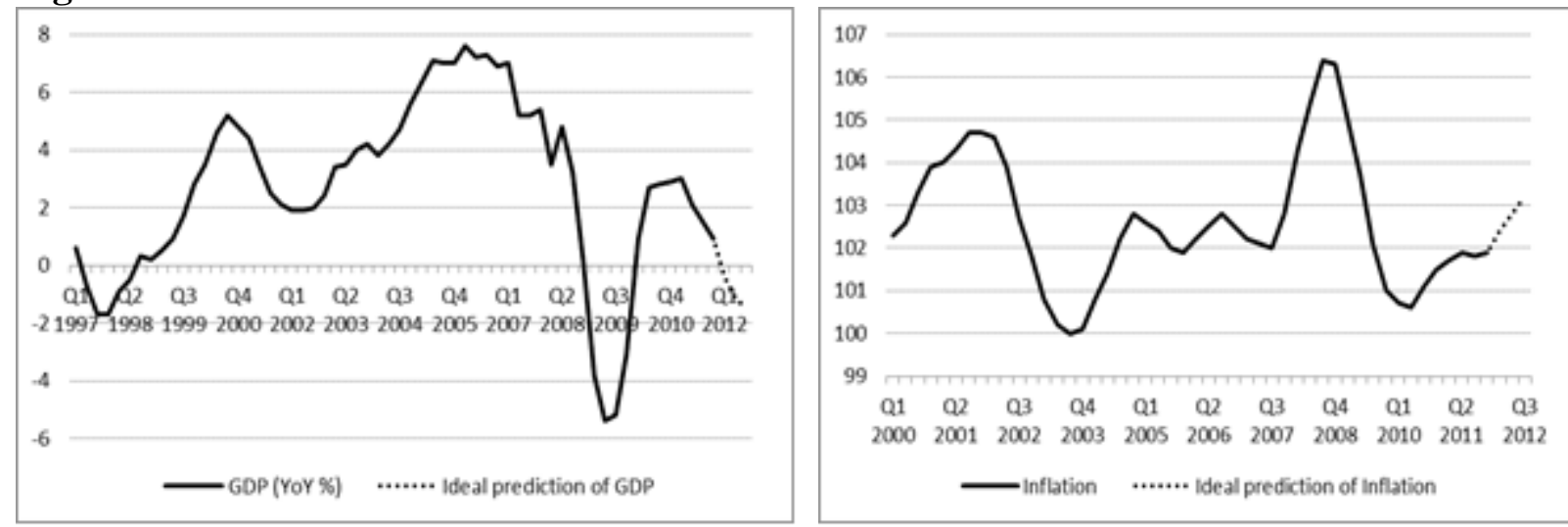

Source: own.

Many methods have to fulfill the assumption of stationarity. Therefore one has to perform this statistical test. The stationarity may be verified by looking at the data or with the exact statistical tests, see Greene (2012) or Arlt and Arltová (2009). The method used in this paper is a KPSS test, for details see Kwiatkowski (1992). The null hypothesis says that the time series is stationary. This hypothesis is not rejected (significance level is $5 \%$ ) for all of our time series. Finally, we have 60 observations and the time series are from Q1 1997 to Q4 2011. Data from Q1 2012 to Q3 2012 are used for the evaluation of forecasted values. This period was chosen because one already has observed an economic downturn in data. If one decided to choose the period from Q1 2008 to Q4 2009 then there is a problem with data because there is no economic downturn in data. It would be even more challenging than the 
period from Q1 2012 to Q3 2012. It is important to mention that all models except the AR(p) model use both variables (GDP and inflation). AR(p) is univariate technique and for modeling is used only GDP time series. Each method uses different length of time series because different lags are applied in each model. Generally, it can be said that this fact has negligible effect on the final results. On the other hand, models with lower lag are less complex but their advantage is that they may utilize more information from time series. It is important to keep this information in the model.

\section{$3 \operatorname{AR}(\mathbf{p})$}

The first benchmark model is a naive AR(1). This model is further used as a benchmark. The main goal of all further econometric techniques is to overcome this $\operatorname{AR}(1)$. The estimated model is expressed as

$$
G D P_{t}=\alpha G D P_{t-1}+\varepsilon_{t},
$$

where the GDP at time $t$ is explained only by the GDP at time $t-1$. GDP is transformed to the year over year percentage changes as is described in chapter 2. The estimation of (2) is performed by an Ordinary Least Squares (OLS) method. For details about AR(1) see Arlt and Arltová (2009).

\section{$4 \operatorname{VAR}(\mathbf{p})$}

The second model used in this paper is a Vector Auto Regression (VAR) model which is a statistical model used to capture the linear interdependencies among multiple time series. Endogenous variables in the VAR are treated symmetrically in a structural sense (although the estimated quantitative response coefficients will not in general be the same); each variable has an equation explaining its evolution based on its own lags and the lags of the other model variables. VAR modeling does not require as much knowledge about the forces influencing a variable as do structural models with simultaneous equations: The only prior knowledge required is a list of variables which can be hypothesized to affect each other inter temporally. VAR models are estimated using the OLS method. For details see Hušek (2007). In accordance with the Schwarz Bayesian criterion (BIC), VAR(2) is estimated which is constructed as follows

$$
y_{t}=\delta+\Pi_{1} y_{t-1}+\Pi_{2} y_{t-2}+v_{t},
$$

where $\delta$ is a vector of level constants, $y$ is a vector of the observed current and lagged endogenous variables, $\Pi_{i}$ is a matrix of the unknown parameters of endogenous variables and $v$ is a vector of normally distributed error terms. Two endogenous variables are used for the prediction of GDP growth: the logarithmic differences of GDP and unemployment. As is mentioned in chapter 2, both endogenous variables fulfill the assumption of stationarity.

\section{BVAR(p)}

Consider the following $\operatorname{VAR}(p)$ model

$$
y_{t}=y_{t-1} \beta_{1}+\ldots+y_{t-p} \beta_{p}+x_{t} \alpha+u_{t},
$$

where $t=1 \ldots T$ is the time index, $y_{t}$ is a column vector of endogenous variables, $x_{t}$ is a column vector of exogenous variables, $u_{t} \in N\left(0, \Sigma_{u}\right)$ is the vector of i.i.d. residuals, $\Sigma$ is $n y \times n y$ matrix, $\beta_{1}, \ldots, \beta_{p}$ are $n y \times n y$ matrices and $\alpha$ is $n y \times n y$ matrix. The matrix form of the Bayesian form of our VAR model is

$$
Y=X \Phi+U .
$$


In other words it can be written as

$$
Y=\left[\begin{array}{c}
y_{1} \\
\vdots \\
y_{T}
\end{array}\right] \quad X=\left[\begin{array}{cccc}
y_{0} & \ldots & y_{1-p} & x_{1} \\
\vdots & \ddots & \vdots & \vdots \\
y_{T-1} & \ldots & y_{T-p} & x_{T}
\end{array}\right] \quad \Phi=\left[\begin{array}{c}
\beta_{1} \\
\vdots \\
\beta_{p} \\
\alpha
\end{array}\right] .
$$

Before the Bayesian estimation one needs to define a prior distribution over the parameters $\Phi$ and $\Sigma$. Priors are made of three components: diffuse prior, dummy observations prior and training sample prior. For more details about prior construction see Doan (1984). For more details about the BVAR theory see Koop (2003). The final estimation is performed using the Matlab routines developed by Sims (2003) and the same data as in the case of the VAR(2) model are used.

\section{New Keynesian DSGE model}

The New Keynesian model (NKM) is formulated according to Galí (2008) and consists of three economic agents. Households purchase goods for consumption, hold money and bonds, supply labor, and maximize the expected present value of utility. Firms hire labor, produce and sell differentiated products in monopolistically competitive goods markets, and maximize profits. The central bank controls the nominal rate of interest. Figure 2 shows the basic structure and dynamics of the NKM.

The NKM consists of six general equilibrium equations which are derived in appendix and two stochastic shocks definitions. All equations are log-linearized and variables denoted by wave are gap variables. Let's start with the dynamic IS equation

$$
\tilde{y}_{t}=-\frac{1}{\sigma}\left(i_{t}-E_{t}\left\{\pi_{t+1}\right\}-r_{t}^{n}\right)+E_{t}\left\{\tilde{y}_{t+1}\right\},
$$

where $\tilde{y}_{t}$ is the output gap, $i_{t}$ is the short term nominal rate, $E_{t}\left\{\pi_{t+1}\right\}$ is the expected inflation in the next period, $r_{t}^{n}$ is the natural rate of interest, $E_{t}\left\{\tilde{y}_{t+1}\right\}$ represents the expected output gap in the next period and finally the parameter $\sigma$ is the coefficient of risk aversion.

Figure 2: The structure of the New Keynesian model

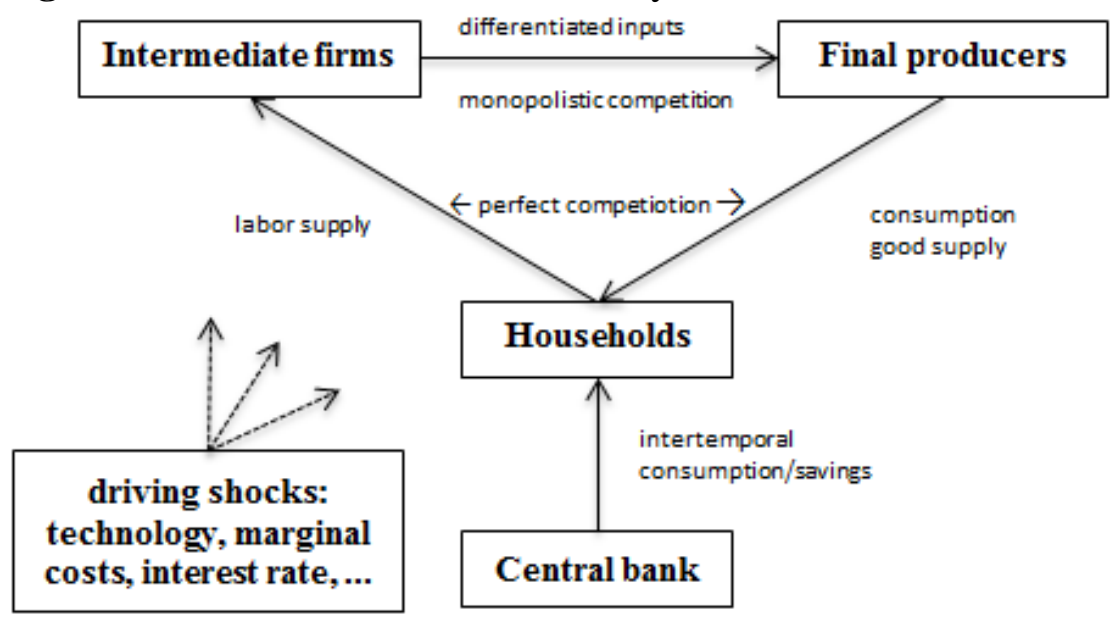

Source: own. 
The second equation is called the New Keynesian Phillips curve (NKPC)

$$
\pi_{t}=\beta E_{t}\left\{\pi_{t+1}\right\}+\kappa \tilde{y}_{t},
$$

where $\pi_{t}$ is the inflation, $\beta$ is the household discount factor, $\kappa \equiv \lambda\left(\sigma+\frac{\phi+\alpha}{1-\alpha}\right)$ and it is the output gap elasticity of inflation, $\sigma$ is the coefficient of risk aversion, $\phi$ is the elasticity of labor supply, $\alpha$ is the share of capital and $\lambda=\frac{\theta^{-1}(1-\theta)(1-\beta \theta)(1-\alpha)}{(1-\alpha+\alpha \varepsilon)}$.

The third equation shows the evolution of the natural rate of interest

$$
r_{t}^{n}=\rho+\sigma \psi_{y a}^{n} E_{t}\left\{\Delta a_{t+1}\right\},
$$

where $r_{t}^{n}$ is the natural rate of interest, $\rho$ is the real interest rate in the steady state, $\psi_{y a}^{n}=\frac{1+\phi}{\sigma(1-\alpha)+\phi+\alpha}$ and $E_{t}\left\{\Delta a_{t+1}\right\}$ is the expected change of technology progress in the next period.

The fourth equation is the interest rate rule of the central bank, usually called a Taylor rule. For details see Taylor (1993)

$$
i_{t}=\rho+\phi_{\pi} \pi_{t}+\phi_{y} \tilde{y}_{t}+v_{t}
$$

where $i_{t}$ is the nominal interest rate, $\phi_{\pi}$ and $\phi_{y}$ is the sensitivity of the central bank with respect to inflation and output gap (both are chosen by the central bank), $v_{t}$ is an exogenous stochastic component with a zero mean.

The fifth equation represents the production function consisting of technology and labor

$$
y_{t}=a_{t}+(1-\alpha) n_{t},
$$

where $y_{t}$ is the output, $a_{t}$ is the level of technology and $n_{t}$ is the number of worked hours.

The sixth equation is the ad-hoc money demand

$$
m_{t}=\pi_{t}+\tilde{y}_{t}-\eta i_{t}
$$

where $m_{t}$ is the money demand, $\eta$ is the elasticity of the money demand with respect to the nominal interest rate.

The last two equations represent the stochastic shocks. The first one is a technology shock which follows the $\mathrm{AR}(1)$ process

$$
a_{t}=\rho_{\alpha} a_{t-1}+\varepsilon_{t}^{a},
$$

where the persistence of the technology shock $\rho_{\alpha} \in[0 ; 1]$ and $\varepsilon_{t}^{a}$ is a zero mean white noise process.

The second is a monetary policy shock which follows the AR(1) process

$$
v_{t}=\rho_{v} v_{t-1}+\varepsilon_{t}^{v}
$$

where the persistence of the monetary policy shock $\rho_{v} \in[0 ; 1]$. Positive (negative) realization of $\varepsilon_{t}^{v}$ is interpreted as a contractionary (expansionary) monetary policy shock, leading to a rise (decline) in the nominal interest rate, given inflation, and the output gap. The NKM model contains the same observable variables as $\operatorname{VAR}(2)$ and $\operatorname{BVAR}(2)$ models. It keeps consistency and comparability of these models. The estimation is performed using the Dynare which is the most powerful Matlab package that can be used for the estimation of general equilibrium models. The model is considered as fully calibrated and it means that all parameters in the model have fixed values or if they are estimated then there is some prior distribution for these parameters set. The priors of the parameters $\alpha, \beta, \phi_{\pi}, \phi_{y}$ are taken from 
the HUBERT model which is used by the Ministry of Finance of the Czech Republic, see Stork et al. (2009). The rest of parameters are calibrated according Galí et al. (2001). These were valid for the US economy, thus I expect that these priors are in accordance with the Czech economy. For detailed calibration see Table 1.

Table 1: The calibration of all structural parameters

\begin{tabular}{|c|c|l|}
\hline Parameter & Prior & Description \\
\hline$\alpha$ & 0.5 & share of capital \\
\hline$\beta$ & 0.99 & discount factor \\
\hline$\varepsilon$ & 1.5 & elasticity of substitution, $m=\log (\varepsilon) /(\varepsilon-1), m=1.1$ \\
\hline$\lambda$ & 0.698 & measure of price stickiness, $0=$ prices are absolutely flexible \\
\hline$\rho$ & 0.154 & $\lambda=\theta^{-1}(1-\theta)(1-\beta \theta)(1-\alpha) /(1-\alpha+\alpha \varepsilon)$ \\
\hline$\sigma$ & $-\log (\beta)$ & real interest rate in the steady state, $\rho=0.0101$ \\
\hline$\phi$ & 1 & coefficient of risk aversion \\
\hline$\phi_{\pi}$ & 1 & elasticity of labor supply \\
\hline$\phi_{y}$ & 0.25 & sensitivity of the central bank with respect to the inflation \\
\hline$\rho_{a}$ & 0.975 & persitivity of the central bank with respect to the output gap \\
\hline$\rho_{v}$ & 0.5 & persistence of the monetary policy shock \\
\hline$\eta$ & 4 & elasticity of money demand with respect to the nominal interest rate \\
\hline
\end{tabular}

Source: own.

The equilibrium of the NKM is characterized by the equations (7) - (14). These equations are rewritten into the Dynare. It is an open-source add-on which works in Matlab or Octave. For more details see Adjemian (2012). In the Dynare a comprehensive package of Bayesian techniques is implemented which are used for the estimate. These techniques are described in Koop (2003) or Hamilton (1994). The algorithm which is implemented in the Dynare is described in Schorfheide (2000) and if you want to learn with the Dynare package then read Griffoli (2010). The whole process of the estimation of DSGE models is described by Villaverde (2009). The main goal is to find the posterior distribution of all unknown parameters (conditional on observed data) and it is performed by using the Bayesian rule for the conditional probability. The posterior distribution is obtained by the combination of a likelihood function and prior distributions of estimated parameters. The likelihood function is estimated by the Kalman filter. The posterior distribution is very often an unknown distribution and thus it is necessary to use a numerical technique to generate the random samples. The Dynare uses for this purpose the Metropolis-Hastings algorithm. This algorithm allows the calculation of the basic statistics and moments.

Table 2 contains parameter estimates. One may see that the prior and the posterior values are similar. It means that the prior values were correctly calibrated. On the other hand there are very wide confidence intervals. It is caused by the short time series. The Czech economy offers only 51 observations and it is not sufficient. If the results of the estimation are inserted into (10) we can see that the central bank is very sensitive on the level of inflation $\left(\phi_{\pi}\right)$. On the other hand, the sensitivity on the output gap $\left(\phi_{y}\right)$ is not very stunning. The elasticity of labor supply $(\phi)$ is calibrated to one and the posterior mean is 0.79 that means that the labor supply is not elastic in the Czech Republic. The share of capital is equal to 0.50 which means 
that the share of labor is also 0.50. This knowledge can be used for the future calibration of the Cobb-Douglas production function.

Table 2: Estimation results

\begin{tabular}{|c|l|l|l|l|l|l|}
\hline parameter & prior & posterior & lower & upper & distribution & pst. dev. \\
\hline$\alpha$ & 0.50 & 0.4978 & 0.4177 & 0.5791 & beta & 0.05 \\
\hline$\phi$ & 1.00 & 0.7928 & 0.7140 & 0.8744 & beta & 0.05 \\
\hline$\phi_{\pi}$ & 1.50 & 1.4946 & 1.4144 & 1.5810 & norm & 0.05 \\
\hline$\phi_{y}$ & 0.25 & 0.2416 & 0.1695 & 0.3206 & norm & 0.05 \\
\hline
\end{tabular}

Source: own.

\section{DSGE-VAR}

This concept is based on the recognition of Sims (1980) that there is a tight relationship between dynamic equilibrium models and VARs. Let us imagine the following experiment, where for the moment the vector of the DSGE model parameters is fixed. One million observations are generated from the DSGE model. We generate a sequence of shocks (monetary and technology), feed them through the DSGE model and obtain artificial data. Next, one estimates a VAR with $p$ lags on these artificial data. If the DSGE model is covariance stationary, then the estimated VAR provides an approximation to the DSGE model with the property that its first $p$ autocovariances of the DSGE model. By including more and more lags one can match more and more autocovariances and increase the accuracy of the VAR approximation of the DSGE model. Now let us imagine that the data generation is repeated by using different parameter values for the DSGE model. As long as the DSGE model parameter space is small compared to the VAR parameter space, a restriction function can be traced that maps the DSGE parameters into a VAR parameter subspace. Hence, estimating a DSGE model is almost like estimating a VAR with cross-equation restriction. Instead of dogmatically imposing the cross-coefficient restrictions implied by the DSGE model on the VAR, one will allow for deviations. The overall magnitude of these deviations is controlled by a hyperparameter, $\lambda$. Roughly speaking, if $\lambda=\infty$, then the restrictions are strictly enforced, whereas if $\lambda=0$, the restrictions are completely ignored in the estimation of the VAR parameters. Computational details are described by Del Negro and Schorfheide (2004).

\section{Results}

Models which are specified in this paper are assessed by the RMSE which is defined by (1). This RMSE is able to assess the power of prediction. The lower value of the RMSE is better fit to empirical data. The summarization of the RMSE and predictions of GDP are in Table 3.

Table 3: Root Mean Square Error (RMSE) of the estimated models

\begin{tabular}{|l|r|r|r|r|}
\hline \multicolumn{1}{|c|}{ Model } & \multicolumn{1}{c|}{ RMSE } & Q1 2012 & Q2 2012 & Q3 2012 \\
\hline AR(1) & 2.2375 & 1.0 & 1.2 & 1.3 \\
\hline VAR(2) & 2.4019 & 1.1 & 1.3 & 1.6 \\
\hline BVAR(2) & 2.5249 & 1.3 & 1.4 & 1.6 \\
\hline DSGE & 1.5041 & 0.6 & 0.4 & 0.4 \\
\hline DSGE-VAR(2) & 2.0496 & 1.2 & 1.0 & 0.9 \\
\hline
\end{tabular}

Source: own.

Figure 3 (left graph) shows the time series of the percentage YoY GDP growth which is a target and predictions (right graph) obtained by methods described in previous chapters. 
As one can see in Figure 3 and Table 3 the naive AR(1) model does not fit the observed GDP very well. On the other hand, this benchmark is not overcome by $\operatorname{VAR}(2)$ and $\operatorname{BVAR}(2)$. This fact is caused by the main characteristics of both models. They obtain information only from historical values of the observed variables. The most appropriate econometric tool is the DSGE model. This result is mainly caused by the specification of the model. The DSGE model consists of structural equations and contains rational expectations. These properties improve forecast in periods with sudden changes. The DSGE-VAR model is the second best performing method. It works like VAR(2) but priors are obtained from the DSGE model.

Figure 3: YoY growth of GDP (left) and predictions (right)
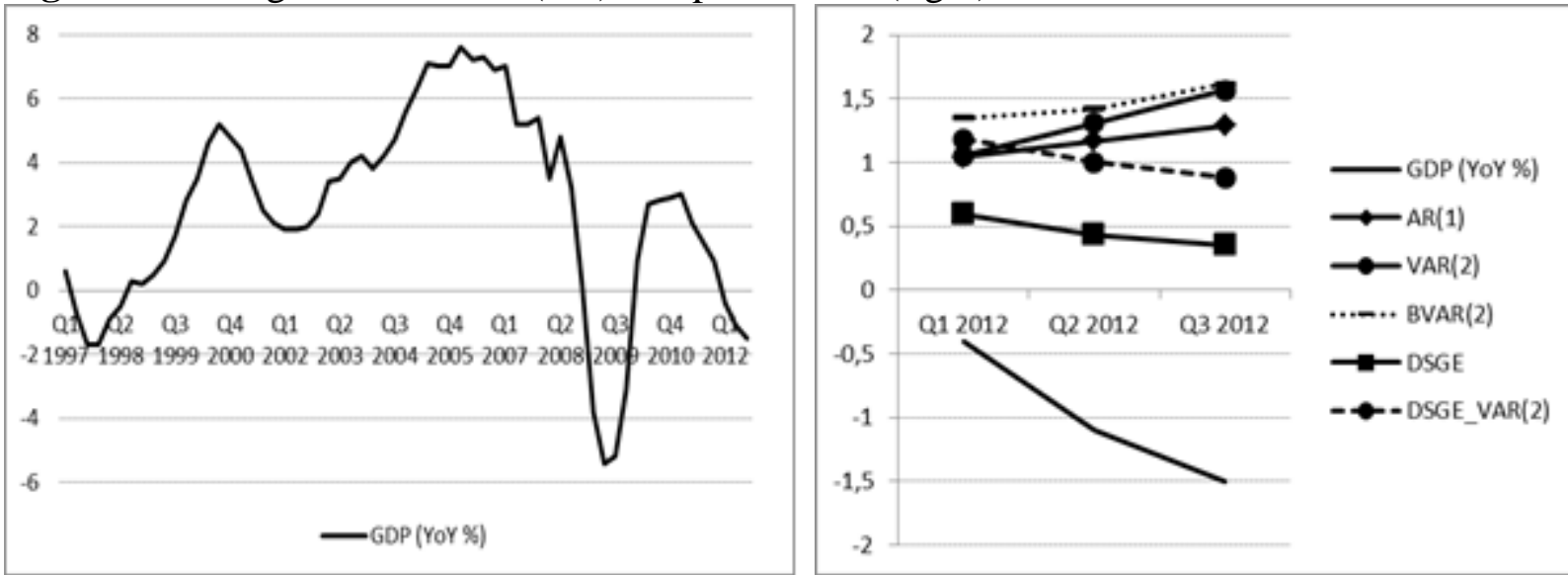

Source: own.

\section{Conclusion}

The paper deals with forecasting the ability of the most common macroeconomic methods. The main goal is to predict the percentage GDP growth while using many methods and at the end assess the performance of these methods. Models are estimated in the training period from Q1 1997 to Q4 2011 and validated in the period from Q1 2012 to Q3 2012. The validation is measured by the Root Mean Square Error (RMSE) statistics. Methods used in this paper are: Auto Regression with one lag (AR(1)), Vector Auto Regression with two lags (VAR(2)), Bayesian Vector Auto Regression with two lags (BVAR(2)), Dynamic Stochastic General Equilibrium (DSGE) and Dynamic Stochastic General Equilibrium - Vector Auto Regression (DSGE-VAR) which obtains priors from the DSGE model and then estimates it like VAR(2). Another contribution of this paper is the specification of the New Keynesian (NK) DSGE model which is taken from Galí (2008) and coding of this model in Matlab. The NK model is specified as a closed economy model which is a certain simplification. The open-economy model is more complex and generally one can expect that the performance of this model would be better in case of the Czech Republic. Models specified in this paper are theoretically described and for the inquisitive reader there are also many references to foreign and domestic literature. Final results are interpreted as follows. The VAR(2) and BVAR(2) models perform worse than the benchmark AR(1) model which is caused by fact that these models obtain only historical information and this history is limiting these models. On the other hand, structural models as the DSGE and DSGE-VAR perform better than a benchmark. In case of the DSGE model it is mainly caused by its structural specification. This model also contains forward looking variables which take into account the natural behavior of households and firms. These two agents (households and firms) are basic cornerstones of the NK DSGE model. The DSGE-VAR model performs well due to fact that priors are taken from the DSGE model. It means that structural information can be transferred by using these priors. 
Nevertheless, according to the RMSE statistics the best performing method is the DSGE model.

\section{Acknowledgement}

This paper is supported by Grant No. IGA F4/24/2014, FIS, University of Economics, Prague.

\section{References}

[1] ADJEMIAN, S., 2012. Dynare: Reference Manual, Version 4. Dynare Working Papers, vol. 1.

[2] ARLT, J. a M. ARLTOVÁ, 2009. Ekonomické časové řady. Praha: Professional Publishing. ISBN 978-808-6946-856.

[3] DEL NEGRO, M. and F. SCHORFHEIDE, 2004. Policy predictions if the model doesn't fit. Federal Reserve Bank of Atlanta Working Paper 2004-38. Available from: http://ssrn.com/abstract $=665190$

[4] DOAN, T., R. B. LITTERMAN and C. A. SIMS, 1984. Forecasting and Conditional Projections Using Realistic Prior Distributions. Econometric Reviews, 3(1), 1-100. ISSN 0747-4938.

[5] GALÍ, J., 2008. Monetary policy, inflation, and the business cycle: an introduction to the new Keynesian framework. Princeton University Press. ISBN 06-911-3316-6.

[6] GALÍ, J., M. GERTLER and J. D. LOPEZ-SALIDO, 2001. European inflation dynamics. European Economic Review, vol. 45(7), 1237-1270. ISSN 0014-2921.

[7] GREENE, W., 2012. Econometric analysis. 7th ed. Boston: Prentice Hall. Pearson series in economics. ISBN 978-0-13-139538-1.

[8] GRIFFOLI, T. M., 2010. Dynare User Guide [online]. [cit. 2013-03-24]. Available from: http://www.dynare.org/documentation-and-support/manual

[9] HAMILTON, J. D., 1994. Time series analysis. Princeton: Princeton University Press, xiv. ISBN 06-910-4289-6.

[10] HUŠEK, R., 2007. Ekonometrická analýza. Praha: Vysoká škola ekonomická v Praze. ISBN 978-80-245-1300-3.

[11] KOOP, G., 2003. Bayesian econometrics. Hoboken, N.J.: J. Wiley, xiv. ISBN 04-7084567-8.

[12] KOOP, G. and D. KOROBILIS, 2009. Bayesian Multivariate Time Series Methods for Empirical Macroeconomics. Working Paper Series, 09(47). The Rimini Centre for Economic Analysis.

[13] KWIATKOWSKI, D., P. PHILLIPS, P. SCHMIDT and Y. SHIN, 1992. Testing the Null Hypothesis of Stationarity Against the Alternative of a Unit Root. Journal of Econometrics, 54(1-3), 159-178. ISSN 0304-4076.

[14] SIMS, C., 2003. Matlab Procedures to Compute Marginal Data Densities for VARs with Minnesota and Training Sample Priors. Department of Economics, Princeton University.

[15] SIMS, C., 1980. Comparison of Interwar and Postwar Business Cycles: Monetarism Reconsidered. NBER Working Papers no. 430. Cambridge: National Bureau of Economic Research, Inc. 
[16] SCHORFHEIDE, F., 2000. Loss Function Based Evaluation of DSGE Models. Journal of Applied Econometrics, 15(6), 645-670. ISSN 1099-1255.

[17] ŠTORK, Z., J. ZÁVACKÁ a M. VÁVRA, 2009. HUBERT: a DSGE model of the Czech economy. Working Paper of Ministry of Finance of the Czech Republic, vol. 2, 1-39. Available at: http://www.mfcr.cz/en/about-ministry/research\#working

[18] TAYLOR, J. B., 1983. Discretion versus policy rules in practice. Journal of business and Economic Statistics, 19. ISSN 0735-0015.

[19] VILLAVERDE, J. F., 2009. The Econometrics of DSGE models. NBER Working Papers no. 1467. Cambridge: National Bureau of Economic Research, Inc. 